\title{
ECAR-3873 Acceptance of Nonconforming Fuel for the AGR-5/6/7 Irradiation Experiments
}

D. W. Marshall

September 2017

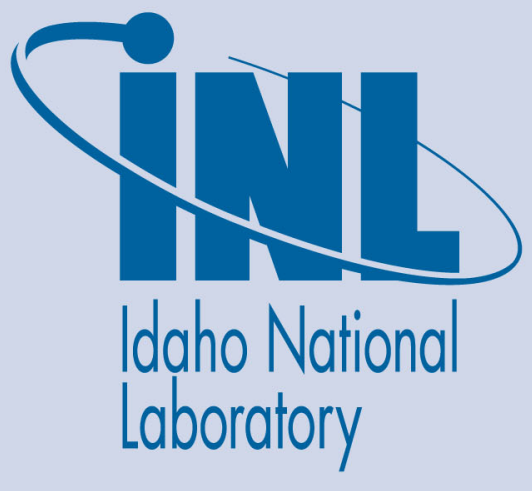

The INL is a U.S. Department of Energy National Laboratory operated by Battelle Energy Alliance 


\title{
ECAR-3873 Acceptance of Nonconforming Fuel for the AGR-5/6/7 Irradiation Experiments
}

\author{
D. W. Marshall
}

September 2017

Idaho National Laboratory Idaho Falls, Idaho 83415

http://www.inl.gov

Prepared for the

U.S. Department of Energy

Under DOE Idaho Operations Office

Contract DE-AC07-05ID14517 
Rev. 06

Title:

Acceptance of Nonconforming Fuel for the AGR-5/6/7 Irradiation Experiments

ECAR No.: 3873

Rev. No.: 0

Project No.: 23841

Date: $09 / 26 / 2017$

\section{SIGNATURES}

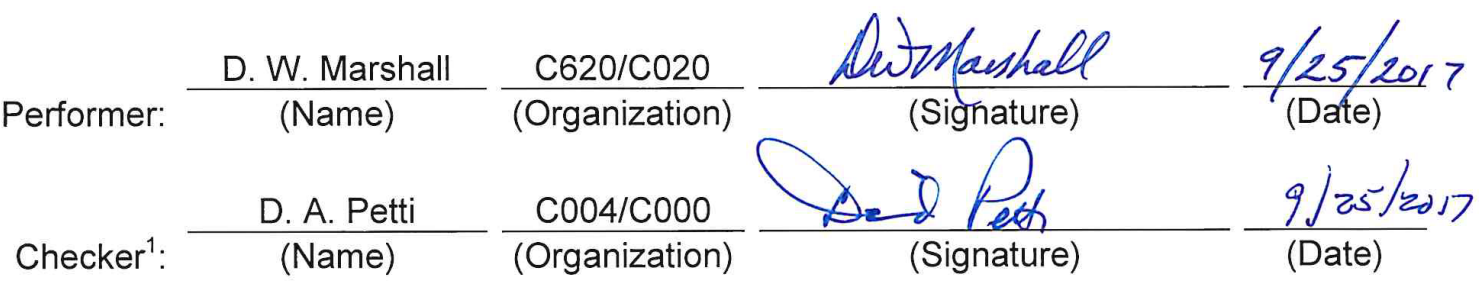

Independent Peer

Reviewer'

$\frac{N A}{(\text { Name })} \frac{\text { NA }}{\text { (Organization) }} \frac{}{\text { (Signature) }} \frac{}{\text { (Date) }}$

CUI Reviewer:

D. E. Raunig

(Name)

$\frac{\mathrm{M} 310}{\text { (Organization) }}$

STIMS INL/MIS-17-43272

$\frac{9 / 18 / 2017}{\text { (Date) }}$

Yes $\square$ or $\mathrm{No}^{5} \otimes$



Nuclear Safety ${ }^{4}$

N/A

$\frac{\mathrm{N} / \mathrm{A}}{(\text { Name })} \frac{}{\text { (Organization) }}$

(Signature)

(Date)

Cognizant Engineer

$\frac{N / A}{(\text { Name })} \frac{}{\text { (Organization) }}$

(Signature)

(Date)

Quality Engineer:

$\frac{\text { Michelle T. Sharp }}{\text { (Name) }} \frac{H 330 / C 020}{\text { (Organization) }} \frac{h \text { S Ahaup }}{\text { (Signature) }} \frac{9 / 26 / 17}{\text { (Date) }}$

1. Confirmation of completeness, mathematical accuracy, and correctness of data and appropriateness of assumptions.

2. Concurrence of method or approach. See definition, LWP-10106.

3. Concurrence of procedure compliance. Concurrence with method/approach and conclusion.

4. Concurrence with the document's assumptions and input information. See definition of Acceptance, LWP-10200.

5. Does the document contain CUI material please check either yes or no. 
TEM-10200-1

$03 / 01 / 2012$

ENGINEERING CALCULATIONS AND ANALYSIS

Page 1 of 10

Rev. 06

Title: $\quad$ Acceptance of Nonconforming Fuel for the AGR-5/6/7 Irradiation Experiments

ECAR No.: 3873

Rev. No.: 0

Project No.: 23841

Date: $09 / 26 / 2017$

\section{REVISION LOG}

\begin{tabular}{|c|c|c|l|}
\hline Rev. & Date & Affected Pages & \multicolumn{1}{|c|}{ Revision Description } \\
\hline 0 & $09 / 26 / 17$ & All & New document \\
\hline & & & \\
\hline & & & \\
\hline & & & \\
\hline & & & \\
\hline & & & \\
\hline & & & \\
\hline & & & \\
\hline & & & \\
\hline & & & \\
\hline
\end{tabular}


TEM-10200-1

$03 / 01 / 2012$

ENGINEERING CALCULATIONS AND ANALYSIS

Page 2 of 10

Rev. 06

Title: $\quad$ Acceptance of Nonconforming Fuel for the AGR-5/6/7 Irradiation Experiments

ECAR No:: 3873

Rev. No.: 0

Project No.:

23841

Date: $09 / 26 / 2017$

\begin{tabular}{|c|c|c|}
\hline 1. Quality Level (QL) No. & QL-3 & \multirow{6}{*}{$\begin{array}{l}\text { Professional Engineer's Stamp } \\
\text { N/A } \\
\text { See LWP-10010 for requirements. }\end{array}$} \\
\hline 2. QL Determination No. & NA & \\
\hline 3. Engineering Job (EJ) No. & NA & \\
\hline 4. SSC ID & NA & \\
\hline 5. Building & $x$ & \\
\hline 6. Site Area & $x$ & \\
\hline
\end{tabular}

7. Objective/Purpose:

Document acceptance of graphitic fuel compacts fabricated for the Advanced Gas Reactor (AGR) irradiation experiments, AGR-5/6/7, despite non-conformance with four fuel specifications.

8. If revision, please state the reason and list sections and/or pages being affected:

9. Conclusions/Recommendations:

The fuel compacts, although not fully conforming to fuel specifications, are of sufficient quality that useful and meaningful data can be collected from the AGR-5/6/7 experiment irradiations.

The fuel compacts are found to be acceptable for the purposes of the irradiations. 
TEM-10200-1

$03 / 01 / 2012$

ENGINEERING CALCULATIONS AND ANALYSIS

Page 3 of 10

Rev. 06

Title: $\quad$ Acceptance of Nonconforming Fuel for the AGR-5/6/7 Irradiation Experiments

ECAR No:: 3873

Rev. No.: 0

Project No::

23841

Date: $09 / 26 / 2017$

\section{CONTENTS}

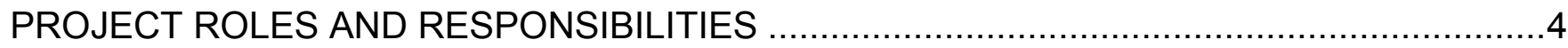

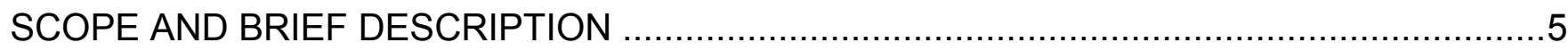

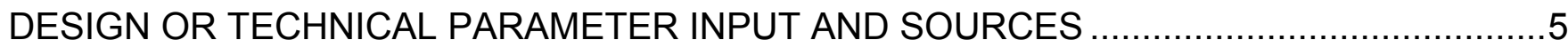

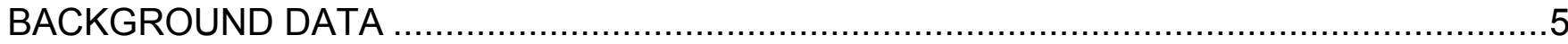

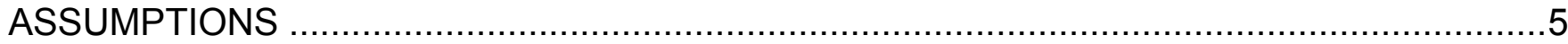

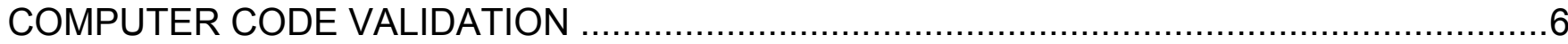

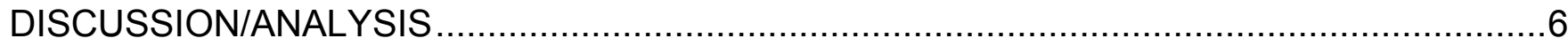

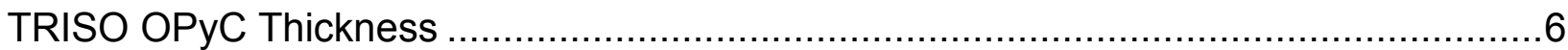

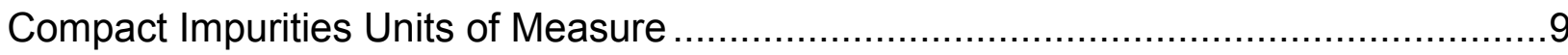

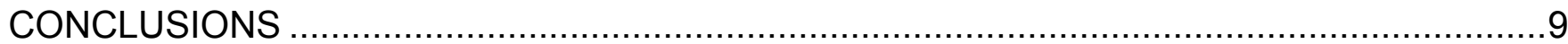

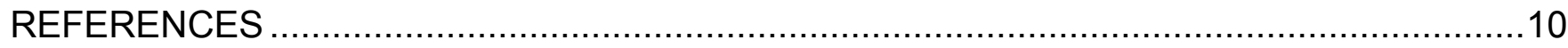

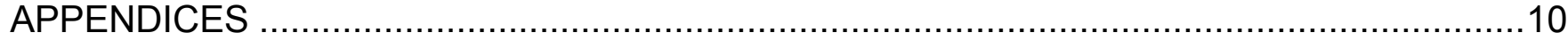

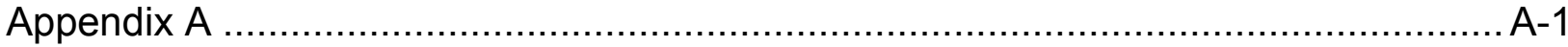

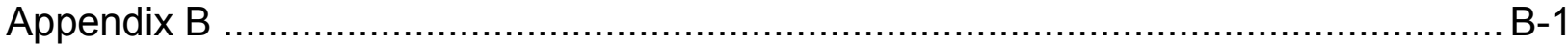

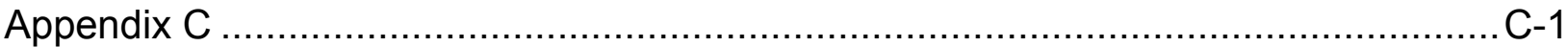




TEM-10200-1

$03 / 01 / 2012$

ENGINEERING CALCULATIONS AND ANALYSIS

Rev. 06

Title: $\quad$ Acceptance of Nonconforming Fuel for the AGR-5/6/7 Irradiation Experiments

ECAR No.: 3873

Rev. No.: 0

Project No.:

23841

Date: $09 / 26 / 2017$

PROJECT ROLES AND RESPONSIBILITIES

\begin{tabular}{l|l|c|c}
\multicolumn{1}{c|}{ Project Role } & \multicolumn{1}{|c|}{ Name (Typed) } & Organization & Pages covered (if applicable) \\
\hline Performer & D. W. Marshall & C620/C020 & \\
Checker $^{a}$ & D. A. Petti & C004/C000 & \\
Independent Reviewer & N/A & \\
CUl Reviewerc & D. E. Raunig & M310 \\
Manager & J. W. Nielsen & C130 \\
Requestore & P. A. Demkowicz & C600/C020 \\
Nuclear Safetye & N/A & \\
Document Ownere & P. A. Demkowicz & C600/C020 &
\end{tabular}

\section{Responsibilities:}

a. Confirmation of completeness, mathematical accuracy, and correctness of data and appropriateness of assumptions.

b. Concurrence of method or approach. See definition, LWP-10106.

c. Concurrence with the document's markings in accordance with LWP-11202.

d. Concurrence of procedure compliance. Concurrence with method/approach and conclusion.

e. Concurrence with the document's assumptions and input information. See definition of Acceptance, LWP-10200.

NOTE: $\quad$ Delete or mark "N/A" for project roles not engaged. Include ALL personnel and their roles listed above in the eCR system. The list of the roles above is not all inclusive. If needed, the list can be extended or reduced. 
TEM-10200-1

$03 / 01 / 2012$

ENGINEERING CALCULATIONS AND ANALYSIS

Page 5 of 10

Rev. 06

Title:

Acceptance of Nonconforming Fuel for the AGR-5/6/7 Irradiation Experiments

ECAR No.: 3873

Rev. No.: 0

Project No.

23841

Date: $09 / 26 / 2017$

\section{SCOPE AND BRIEF DESCRIPTION}

Prismatic Very-High Temperature Reactor (VHTR) fuel fabricated for the Advanced Gas Reactor (AGR) irradiation experiments, AGR-5/6/7, did not meet fuel specifications for the outer pyrocarbon (OPyC) mean thickness or the dispersed uranium fraction (DUF). Fuel was fabricated at two nominal packing fractions, $25 \%$ and $40 \%$. In addition to the nonconforming properties already mentioned, the compacts with $25 \%$ packing fraction (PF) were nonconforming for the silicon carbide defect fraction and the compacts with $40 \%$ PF were nonconforming for the exposed kernel fraction (EKF).

Furthermore, because the impurities outside of the silicon carbide ( $\mathrm{SiC}$ ) layer all measured below the detection limit for the method, on a clutch of five compacts, the results were reported with units " $\mu \mathrm{g} / 5$ compact clutch" and could not be reported with the required units of " $\mu \mathrm{g} / \mathrm{compact."}$

This document describes the reasons why the nonconforming fuel compacts are deemed acceptable to use in the AGR-5/6/7 irradiation experiment.

\section{DESIGN OR TECHNICAL PARAMETER INPUT AND SOURCES}

None

\section{BACKGROUND DATA}

\begin{tabular}{|c|c|c|c|}
\hline Property & Mean $(\mathbf{N})^{a}$ & Mean at $95 \%$ Confidence & Dispersion 0.95/0.99 \\
\hline OPyC Thickness Specification ${ }^{1}$ & --- & $36-44 \mu \mathrm{m}$ & $\leq 20 \mu \mathrm{m}^{\mathrm{b}}$ \\
\hline TRISO lot J52R-16-98005 ${ }^{2}$ & $35.03 \mu \mathrm{m}$ & $34.75 \mu \mathrm{m}(\mathrm{F})$ & $30.76 \mu \mathrm{m}$ \\
\hline Dispersed U Fraction Specification $^{1}$ & -- & $\leq 1.0 \mathrm{e}-5$ & -- \\
\hline TRISO lot J52R-16-98005 2 & $2.28 \mathrm{e}-5$ & --- & --- \\
\hline $40 \%$ PF Compacts ${ }^{3,4}$ & $3.18 e-5$ & $3.80 \mathrm{e}-5(\mathrm{~F})$ & -- \\
\hline $25 \%$ PF Compacts ${ }^{3,4}$ & $2.66 \mathrm{e}-5$ & $2.95 e-5(F)$ & --- \\
\hline Exposed Kernel Fraction Specification ${ }^{1}$ & --- & $\leq 5.0 \mathrm{e}-5$ & --- \\
\hline TRISO lot J52R-16-98005 ${ }^{2}$ & $6.96 \mathrm{e}-6$ & $9.35 e-6(N)$ & --- \\
\hline 40\% PF Compacts ${ }^{3,4}$ & $6.57 e-5$ & $9.28 \mathrm{e}-5(\mathrm{~F})$ & --- \\
\hline $25 \%$ PF Compacts ${ }^{3,4}$ & $7.39 \mathrm{e}-6$ & $1.48 \mathrm{e}-5$ & -- \\
\hline SiC Defect Fraction Specification ${ }^{1}$ & --- & $\leq 1.0 \mathrm{e}-4$ & -- \\
\hline TRISO lot J52R-16-98005 2 & $2.83 e-5$ & $3.27 \mathrm{e}-5(\mathrm{~N})$ & --- \\
\hline 40\% PF Compacts ${ }^{3,4}$ & $6.96 e-5$ & $9.66 \mathrm{e}-5$ & --- \\
\hline $25 \%$ PF Compacts ${ }^{3,4}$ & $9.24 \mathrm{e}-5$ & $1.22 \mathrm{e}-4(\mathrm{~F})$ & --- \\
\hline
\end{tabular}

\section{ASSUMPTIONS}

Not Applicable 
TEM-10200-1

$03 / 01 / 2012$

ENGINEERING CALCULATIONS AND ANALYSIS

Page 6 of 10

Rev. 06

Title: $\quad$ Acceptance of Nonconforming Fuel for the AGR-5/6/7 Irradiation Experiments

$\begin{array}{lllll}\text { ECAR No.: } 3873 & \text { Rev. No.: } 0 & \text { Project No.: } 23841 & \text { Date: 09/26/2017 }\end{array}$

COMPUTER CODE VALIDATION

Not Applicable

\section{DISCUSSION/ANALYSIS}

\section{TRISO OPyC Thickness}

The OPyC layer performs multiple functions. 1) It is to serve as a final barrier to fission product releases, specifically for gaseous fission products. 2) It is known to shrink under fast neutron irradiation and presumed to compressively load the silicon carbide layer; thereby preventing the silicon carbide layer from failing due to hoop stresses caused by internal pressurization (a.k.a. pressure vessel failures; predominately from carbon monoxide accumulation). 3) The OPyC layer provides mechanical protection of the brittle SiC layer during subsequent handling.

The United States Advanced Gas Reactor Program will use a mixed ceramic fuel kernel that is composed of uranium carbides and oxides (UCO). UCO kernels evolve far less CO than urania kernels employed by other countries. Consequently, the internal pressures formed during irradiation are far less and hoop stress failures are effectively prevented. Furthermore, post-irradiation-examinations (PIE) on AGR-1 and AGR-2 fuels show a tendency for the OPyC to shrink away from the SiC vs. towards the $\mathrm{SiC}$ as previously imagined. Therefore, the OPyC layer does not impose a compressive load on the $\mathrm{SiC}$ as thought.

The fuel specification ${ }^{1}$ for the OPyC thickness was based on all three functions, collectively. A major driver for the specification was adequate thickness to enable the OPyC to compress the SiC layer without cracking. Since the OPyC layer does not compress the SiC, as envisioned, and because thinner OPyC layers still adequately perform the functions of retaining gaseous fission products and protecting the $\mathrm{SiC}$ layer from mechanical damage, an OPyC thickness of $\sim 35 \mu \mathrm{m}$ will be sufficient and no degradation of the TRISO in-pile performance is expected due to the mean thickness being slightly below the specification at $95 \%$ confidence.

The narrowly distributed OPyC thicknesses keep the lower tail of the distribution well above the critical limit of $20 \mu \mathrm{m}$, which further supports the argument that the thickness will be adequate for the functions that it performs.

The AGR Technical Coordination Team (TCT) was consulted ${ }^{5}$ before the TRISO batches were selected for composing the TRISO lot, knowing that conformance to the OPyC thickness specification could be jeopardized by the selection of batches. The TCT recommendation was: "BWXT TRISO coating batches 93165,93168 and 93169 should be included in the coated particle composite to be used for AGR-5/6/7 compact formation," with full knowledge that inclusion of TRISO batch J52O-1693165 would result in the mean OPyC thickness failing the fuel specification.

INL instructed BWXT to compose the TRISO lot from TRISO batches J52O-16-93165, 93168, 93169, and $93170{ }^{6}$. BWXT issued a Quality Control Deficiency Notice (QCDN) ${ }^{7}$ documenting that the composited TRISO lot did not meet the mean OPyC specification. The QCDN was accepted by INL with the disposition of "Approve as is." 
TEM-10200-1

$03 / 01 / 2012$

ENGINEERING CALCULATIONS AND ANALYSIS

Page 7 of 10

Rev. 06

Title: $\quad$ Acceptance of Nonconforming Fuel for the AGR-5/6/7 Irradiation Experiments

$\begin{array}{lllll}\text { ECAR No.: } 3873 & \text { Rev. No.: } 0 & \text { Project No.: } 23841 \quad \text { Date: 09/26/2017 }\end{array}$

\section{Compact Defect Fractions}

The three defects that are quantified by the compact deconsolidation-leach-burn-leach (DLBL) method are the dispersed uranium fraction (DUF), exposed kernel fraction (EKF), and the silicon carbide defect fraction. The total contribution of all defects (DUF, EKF, and porous $\mathrm{SiC}$ ) is to be kept below an effective 2e-4 defect level in a VHTR reactor to enable maintenance of heat transfer units and to prevent excessive off-site releases during accident events. The total allowable defect level is subdivided between the three defect fractions. Fission product releases from DUF is thought to be an order of magnitude higher, for a given mass of uranium, than releases from dense kernels with either cracked layers or porous $\mathrm{SiC}$, thus the allowable defect level for DUF has been assigned a lower limit than the other two fractions.

Particulars of the three defect fractions are discussed individually below. The levels of the defects, which are higher than intended, were evaluated by INL and the TCT prior to accepting the fuel for use for the AGR-5/6/7 experiment irradiation ${ }^{8}$. The reasons for accepting the fuel as-is include: 1) The fuel specifications were written for fuel to be used in a future VHTR reactor and not specifically written to safeguard data collection for an experiment irradiation. 2) The defect levels are high enough to complicate analysis of fuel performance data, but are not so high as to preclude "seeing" in-pile TRISO particle failures and collecting valuable data from the irradiation of the fuel. 3) Commercial VHTR fuel would need to undergo a "proof" test and not rely solely on AGR-5/6/7 data. 4) Refabricating the fuel would guarantee improved attributes. The required time to investigate the cause(s) of increasing defect levels during overcoating and compaction, in addition to that needed for fuel refabrication, would likely result in lost access to the Advanced Test Reactor Northeast flux trap, which is essential for irradiating a test train of the size designed for AGR-5/6/7.

Samples of overcoated TRISO particles for $40 \%$ PF compacts and compacts of both packing fractions are being analyzed at Oak Ridge National Laboratory for the three defect fractions to confirm the compact defect data obtained by BWX Technologies and to get a metric of damage done during deposition of the resinated graphite overcoat on the TRISO. The data are not available at this time.

\section{Dispersed Uranium Fraction}

Dispersed uranium fraction (DUF) is a variable property used to estimate the quantity of uranium outside of the $\mathrm{SiC}$ coating layer in the TRISO and compact. It is postulated that uranium can be incorporated into the OPyC layer from contamination on the coater walls or associated with the resinated graphite matrix. Impurities analyses of the components for the resinated graphite matrix preclude incorporation of significant natural uranium, leaving uranium contamination as the only true source.

DUF is quantified by assuming any quantity of uranium leached from the liberated TRISO particles amounting to less than one-half kernel equivalent, in the deconsolidating acid or in the pre-burn and post-burn leach sequences, is from contamination and that anything greater than this is from exposed kernels in cracked/broken particles or from porous silicon carbide layers. An intact OPyC layer is impervious to the acid used to deconsolidate the compact or leach prior to burning back the OPyC, so not much more than surface contamination should be detected with the pre-burn leaches. Burning back the OPyC liberates the remainder of the uranium embedded within the OPyC and making it accessible to the post-burn leach acids. The DUF is reported as the sum of the uranium recovered from all leaches combined, that are not attributed to either broken or porous coating layers. 
TEM-10200-1

$03 / 01 / 2012$

ENGINEERING CALCULATIONS AND ANALYSIS

Page 8 of 10

Rev. 06

Title: $\quad$ Acceptance of Nonconforming Fuel for the AGR-5/6/7 Irradiation Experiments

$\begin{array}{lllll}\text { ECAR No.: } 3873 & \text { Rev. No.: } 0 & \text { Project No.: } & 23841 & \text { Date: } 09 / 26 / 2017\end{array}$

Leach-burn-leach tests on the TRISO lot indicated that the compacts would likely fail the DUF defect fraction. Because the estimated EKF and SiC defects for the TRISO lot would pass the compact specification, the TRISO was deemed acceptable. If the metric for DUF is accurate, then these defects should be unaffected during fuel compact formation. Comparison of the DUF calculated for the TRISO lot and the two compact packing fractions shows some increase in the DUF value; $25 \%$ PF increasing by $\sim 16 \%$ and $40 \%$ PF by $\sim 39 \%$.

\section{Exposed Kernel Fraction}

The exposed kernel fraction (EKF) is an attribute property estimating the fraction of damaged TRISO particles with cracked or broken coating layers such that the kernel is, at least, partially exposed. Even severely cracked coating layers and the fuel kernel, itself, retard the release of some fission products better than dispersed uranium. The TRISO particles are thought to incur damage by vacuum unloading of the TRISO (possibly only as incipient damage), during overcoating of particles with the resinated graphite matrix, and during fuel compact formation. The latter being the most significant source of damage or the process that exacerbates the incipient damage incurred in earlier processing steps.

TRISO lot data indicated that the EKF defect level was about $20 \%$ of the specification limit with a $95 \%$ confidence, suggesting that compacted fuel would conform to the specification. Some small increase in the EKF is suggested by the data for the $25 \%$ PF compacts, but it easily passed the specification requirement. The EKF for the $40 \%$ PF compacts, however, were an order of magnitude higher than the TRISO lot and fail at nearly double the specification limit.

Capsule 1 at the bottom of the test train and Capsule 5 at the top of the test train have compacts with $40 \%$ PF, collectively holding 114 fuel compacts. Capsules 2, 3, and 4 hold, collectively, 80 compacts at $25 \%$ PF. Irradiation of the $25 \%$ PF compacts is not impacted by high EKF of the $40 \%$ PF compacts. Capsule 1, with 90 compacts, is the most affected by the high EKF value. An assessment of the defect levels in Capsule 1 indicates that in-pile particle failures would still be detectable and that valuable data can be obtained during the irradiation and in post-irradiation examination (PIE), despite the high EKF value.

The calculated EKF mean and 95\% confidence intervals, reported in the BWX Technologies compact certification package, were adjusted to account for the contribution of DUF in the pre-burn leaches. ${ }^{4}$

\section{Silicon Carbide Defect Fraction}

The silicon carbide defect fraction is an attribute property estimating the fraction of particles with a porous or permeable SiC layer. Even porous SiC layers retain some fission products. Half of the allowable defect fraction for the reactor core is allocated to this $\mathrm{SiC}$ defect. This defect should be independent of the EKF, except as a weak spot where a fracture could initiate during fuel compact forming. The fraction of truly porous SiC layers should not increase during overcoating, compaction, or thermal treatment. Data show, however, that the mean $\mathrm{SiC}$ defect fraction increased to $330 \%$ and $250 \%$ of the TRISO defect level for the $25 \%$ PF and $40 \%$ PF compacts, respectively. This phenomenon is yet to be explained, but is probably due to cracked particle layers that manifested as porous $\mathrm{SiC}$ during the leaches by not allowing for complete leaching of the kernel. Nonetheless, the defects are attributed (by the method) to a SiC defect. The $25 \%$ PF compacts fail to conform to the specification while the $40 \%$ PF compacts barely pass. 
TEM-10200-1

$03 / 01 / 2012$

ENGINEERING CALCULATIONS AND ANALYSIS

Page 9 of 10

Rev. 06

Title: $\quad$ Acceptance of Nonconforming Fuel for the AGR-5/6/7 Irradiation Experiments

$\begin{array}{lllll}\text { ECAR No.: } 3873 & \text { Rev. No.: } 0 & \text { Project No.: } & 23841 & \text { Date: 09/26/2017 }\end{array}$

\section{Compact Impurities Units of Measure}

The fuel specification ${ }^{1}$ and the sampling plan ${ }^{9}$ state that the units for impurities in the compacts be micrograms of the metal impurity outside of the SiC layer per compact. These analyses are performed on leachates generated during the compact deconsolidation-leach-burn-leach procedure for quantifying the DUF, EKF, and SiC defect fractions. A five-compact "clutch" is deconsolidated and leached in this method, so the measured impurities apply to the clutch and not individual compacts. All clutches measured impurities below the established detection limits for all elements of concern. BWX Technologies wrote: ${ }^{10}$

"If the result reported by the analysis was greater than the LDL, then dividing the result by five would produce the desired unit. However, for cases where the reported result was "less than LDL", then dividing the LDL value by five would not be appropriate. That is because the LDL had been determined by the reproducibility of the ppb [parts per billion] calibration curve, which was independent of the number of compacts under test. Therefore, for those samples with elemental results reported at the LDL value, the minimum division possible is the clutch. For those situations, the desired unit of $\mu \mathrm{g} /$ compact cannot be achieved."

INL accepts reporting the compact clutch results, in lieu of compact averages, for this case. The maximum possible impurity per compact is, arguably, no more than the values reported for the clutch, and thereby pass the specification requirement with adequate assurance.

\section{CONCLUSIONS}

The consensus is that the OPyC thickness being below the specified range for the mean will not significantly contribute to in-pile particle failures, because the distribution is narrow and sufficiently high that the probability of having particles with less than a $20 \mu \mathrm{m}$ thickness is very, very remote.

Additionally, the specification for OPyC thickness was partially based on the assumption that shrinking OPyC would compress the SiC layer. Some mounted particles of irradiated fuel from the AGR-1 and AGR-2 fuels show that some OPyC layers shrink radially outward and debond from the SiC layer.

The high DUF and the higher than expected EKF and SiC defects is undesirable and likely would not be accepted use in a VHTR reactor. The defect levels will make detecting in-pile particle failures more difficult, but the judgement of subject matter experts is that our instrumentation will be able to discern the few particle failures that will occur and that valuable data will be obtained from the irradiation of the existing AGR-5/6/7 fuel compacts.

Despite the nonconforming properties of the TRISO and the compacted fuel, it is better to accept the fuel, as-is, than to attempt refabricating the fuel (with no guarantee of improvement) and risk losing access to the ATR Northeast flux trap for the irradiation. 
TEM-10200-1

$03 / 01 / 2012$

ENGINEERING CALCULATIONS AND ANALYSIS

Page 10 of 10

Rev. 06

Title: $\quad$ Acceptance of Nonconforming Fuel for the AGR-5/6/7 Irradiation Experiments

$\begin{array}{lllll}\text { ECAR No.: } 3873 & \text { Rev. No.: } 0 & \text { Project No.: } 23841 & \text { Date: 09/26/2017 }\end{array}$

\section{REFERENCES}

1. SPC-3652, "AGR-5/6/7 Fuel Specification," Rev 8, March 2017.

2. BWXT Advanced Gas Reactor Program (AGR) Contract No. 107790, J52R, Industrial Fuel Fabrication and Development, Lot J52R-16-98005, Book 1 (BWXT N-74 Document Transmittal Form, "Revised Statistical Report on AGR 98005 Blend," Signed June 13, 2017.

3. BWXT Advanced Gas Reactor Program (AGR) Contract No. 107790, J52R, Industrial Fuel Fabrication and Development, LEU Compact Certification Package, Book 1.

4. BWXT N-74 Document Transmittal Form, "Supplemental Information to the AGR 5/6/7 Compact Certification Package," signed September 6, 2017, Re: DUF, EKF, and SiC defect calculations (Appendix A).

5. Technical Coordination Team February 1, 2017 teleconference summary issued February 8, 2017.

6. BWXT N-74 Document Transmittal Form, "Permission to Blend Mixture to Supply Material for AGR Compacting," signed February 20, 2017 (Appendix B).

7. BWXT N-74 Document Transmittal Form, "QCDN for missing OPyC thickness," signed March 21, 2017 (Appendix C).

8. Technical Coordination Team June 5, 2017 teleconference summary issued June 8, 2017.

9. $\quad$ PLN-4352, "Statistical Sampling Plan for AGR-5/6/7 Fuel Materials," Rev. 5, May 2016.

10. BWXT N-74 Document Transmittal Form, "Supplemental Information to the AGR 5/6/7 Compact Certification Package," signed September 12, 2017, Re: Impurities analyses and reported units (Appendix D).

\section{APPENDICES}

A. BWXT N-74 Document Transmittal Form, "Supplemental Information to the AGR 5/6/7 Compact Certification Package," signed September 6, 2017, Re: DUF, EKF, and SiC defect calculations.

B. BWXT N-74 Document Transmittal Form, "Permission to Blend Mixture to Supply Material for AGR Compacting," signed February 20, 2017.

C. BWXT N-74 Document Transmittal Form, "QCDN for missing OPyC thickness," signed March 21, 2017.

D. BWXT N-74 Document Transmittal Form, "Supplemental Information to the AGR 5/6/7 Compact Certification Package," signed September 12, 2017, Re: Impurities analyses and reported units. 
TEM-10200-1

$03 / 01 / 2012$

Rev. 06

ENGINEERING CALCULATIONS AND ANALYSIS

Page $\mathrm{A} 1$ of $\mathrm{A} 4$

Title: $\quad$ Acceptance of Nonconforming Fuel for the AGR-5/6/7 Irradiation Experiments

ECAR No.: 3873

Rev. No.: 0

Project No.:

23841

Date: $09 / 26 / 2017$

Appendix A 
TEM-10200-1

$03 / 01 / 2012$

ENGINEERING CALCULATIONS AND ANALYSIS

Page A2 of A4

Rev. 06

Title: $\quad$ Acceptance of Nonconforming Fuel for the AGR-5/6/7 Irradiation Experiments

$\begin{array}{lllll}\text { ECAR No.: } 3873 & \text { Rev. No.: } 0 & \text { Project No.: } 23841 & \text { Date: } 09 / 26 / 2017\end{array}$




TEM-10200-1

$03 / 01 / 2012$

ENGINEERING CALCULATIONS AND ANALYSIS

Page A3 of A4

Rev. 06

Title: $\quad$ Acceptance of Nonconforming Fuel for the AGR-5/6/7 Irradiation Experiments

ECAR No.: 3873

Rev. No.: 0

Project No.:

23841

Date: $09 / 26 / 2017$

BWXT RTRT

민 002

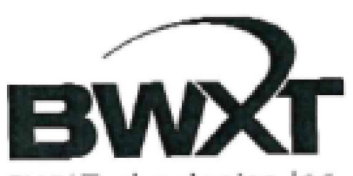

BWX Technologies, Inc.

As part of the certification of the AGR 5/6/7 LEU Compacts, the fraction of the TRISO particles inside each compact was characterized. INL specifications PLN-4352 and SPC-1352 documented the testing requirements and the corresponding limits for each test. A $95 \%$ confidence interval was specified for the failure fraction attributes. Once the raw data had been obtained from the BWXT Chemistry Laboratory, the content was forwarded to the BWXT Statistics Department for statistical characterization. The content below summarizes the fallure fraction testing method and the statistical method that was used for the characterization.

For both the $40 \% \mathrm{PF}$ and the $25 \%$ PF cases, the results from the Chern Lab were reported as equivalent particle failures by 5-compact clutch for each leach operation. The leaches were divided between pre-burn and post burn. All clutches recelved at least one leach operation (pre-burn and post-burn), with some of the clutches receiving three. The results from the leaches were summed into a total before burn and a total after burn. Those clutches where the sum was less than 0.5 equivalent particles were grouped into the DUF attribute and were not considered for the EKF or SIC calculations. Once the DUF had been determined, the result was subtracted from each clutch total. The pre-burn DUF was subtracted from the pre-burn clutch result, and the post-burn DUF was subtracted from the post-burn clutch result. For the EKF attribute, the pre-burn differences were summed, rounded, and divided by the number of particles present in all the clutches. For the SIC attribute, the post-burn differences were summed, rounded, and divided by the number of particles in all the clutches. The result was a total equivalent particle failure fraction representing the pre-burn leaches (EKF) and the postburn leaches (SIC). This information, along with the raw data, was provided to the BWXT Stats group for analysis.

The analysis begran with a review of the Program specifications. PLN-4352 and SPC-1352 were reviewed for the contractual requirements. It was decided that the data would best be represented by a Poisson Distribution. The probability distribution of the Poisson random variable $X$, representing the number of failed particles in a given number of particles is

$$
p(x ; u)=\frac{e^{-u} u^{x}}{x !}
$$

where $u$ is the average number of failures occurring and $e=2.71828$. The probability distribution is calculated for each interval from 0 on, until the cumulative probability hits .95, at which point we can say that we are $95 \%$ confident that the number of particles is less than or equal to the number corresponding to the $95 \%$ curnulative probability.

An example of what this distribution looks like is shown in Figure 1. 
TEM-10200-1

$03 / 01 / 2012$

ENGINEERING CALCULATIONS AND ANALYSIS

Page A4 of A4

Rev. 06

Title: $\quad$ Acceptance of Nonconforming Fuel for the AGR-5/6/7 Irradiation Experiments

ECAR No.: 3873

Rev. No.: 0

Project No.:

23841

Date: $09 / 26 / 2017$


Flezure 1: Example of Polsson Distributlons

For the case of the $40 \%$ PF EKF, the 50th percentile of the curve was centered at the number of pre-burn equivalent particles, or 17. For that curve, the point that represents $95 \%$ of the area under the curve would be 24 . Therefore, there is a $95 \%$ probability that the mean of the distribution is less than or equal to 24. A similar process was used for the $40 \%$ PF SIC attribute and both the $25 \% \mathrm{PF}$ attributes. Once the equivalent particle failures had been determined, each value was divided by the total number of particles tested to generate the failure fraction.

Below is the table containing the failure fraction reported values.

\begin{tabular}{|c|c|c|c|c|c|}
\hline Packing Fraction & Attribute & Mean Result & $95 \%$ Confidence & Spec & Result \\
\hline $40 \%$ & EKF & $6.57 E-05$ & $9.28 E-05$ & $5 S .0 E-05$ & FAIL \\
\hline $40 \%$ & SIC & $6.96 E-05$ & $9.66 E-05$ & $51.0 E-04$ & PASS \\
\hline $25 \%$ & EKF & $7.39 E-06$ & $1.48 E-05$ & $5.0 E-05$ & PASS \\
\hline $25 \%$ & SIC & $9.24 E-05$ & $1.22 E-04$ & $\leq 1.0 E-04$ & FAIL \\
\hline \multicolumn{5}{|c|}{ Table 1: Fallure Fraction Data Summary }
\end{tabular}


TEM-10200-1

$03 / 01 / 2012$

Rev. 06

Title:

Acceptance of Nonconforming Fuel for the AGR-5/6/7 Irradiation Experiments

ECAR No.: 3873
ENGINEERING CALCULATIONS AND ANALYSIS

Page B1 of B4
Rev. No.: 0

Project No.:

23841

Date: $09 / 26 / 2017$

\section{Appendix B}


TEM-10200-1

$03 / 01 / 2012$

ENGINEERING CALCULATIONS AND ANALYSIS

Page B2 of B4

Rev. 06

Title: $\quad$ Acceptance of Nonconforming Fuel for the AGR-5/6/7 Irradiation Experiments

$\begin{array}{lllll}\text { ECAR No.: } 3873 & \text { Rev. No.: } 0 & \text { Project No.: } 23841 \quad \text { Date: 09/26/2017 }\end{array}$

DOCUMENT TRANSMITTAL FORM N-74 Rev. 2 (פ2/26/4)




TEM-10200-1

$03 / 01 / 2012$

ENGINEERING CALCULATIONS AND ANALYSIS

Page B3 of B4

Rev. 06

Title: $\quad$ Acceptance of Nonconforming Fuel for the AGR-5/6/7 Irradiation Experiments

$\begin{array}{lllll}\text { ECAR No.: } 3873 & \text { Rev. No.: } 0 & \text { Project No.: } 23841 \quad \text { Date: 09/26/2017 }\end{array}$

Keeley, Joseph T (Joe)

$\begin{array}{ll}\text { From: } & \text { Douglas Marshall <opamarshall@gmail,com> } \\ \text { Sent: } & \text { Friday, February 17, 2017 10:36 AM } \\ \text { To: } & \text { Keeley, Joseph T Uoe); Marshall, Douglas W } \\ \text { Ce: } & \text { Navolio, David W; Niedzialek, Scott E; Richardson, W C (Clay); Jones, Aaron C; Mulreany, } \\ & \text { Robert E } \\ \text { Subject: } & \text { EXTERNAL:Re: FW: AGR Burn Leach results }\end{array}$

Joe, et al.,

The data look far better than I had hoped for. Both leaches pass the compact specifications at $95 \%$

confidence. We saw, as you stated earlier, more than $50 \%$ reduction of the pre-burn leach and nearly $75 \%$

reduction in the post-burn leach calculated at $95 \%$ confidences.

\begin{tabular}{|c|c|c|c|c|c|c|c|c|}
\hline \multirow{3}{*}{$\begin{array}{c}\quad-\cdots \\
-\cdots+\end{array}$} & \multicolumn{4}{|c|}{ PreBurn Lesdh } & \multicolumn{4}{|c|}{ Post Burn Leach } \\
\hline & \multicolumn{4}{|c|}{ Toted } & \multicolumn{4}{|c|}{ Total } \\
\hline & Felled Part & Pantidex & Fullime frection & $90 \%$ cond. & Felled Part & Epritldes & Fulture Fredtion & sols cont. \\
\hline mign & 22 & 330000 & 67uc-05 & L91Ses & $2 \pi$ & 165000 & LEAE-60 & 4.706 \\
\hline goilena & 157 & 111nodo & L9t5-es & $1.90-6$ & agp & 159000 & 5.7500 & 295te 05 \\
\hline gansen & $\mathbf{a n}$ & 324000 & 1.ES0S & 2AESOS & 227 & 162000 & LAEE-OS & I.ES-05 \\
\hline gavean & 10.31 & 1200 & $3.00-0$ & 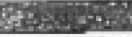 & 2.56 & 162000 & $17 \overline{\operatorname{tas}}$ & $47 x-05$ \\
\hline 931704 & & & 215-es & $40 \mathrm{ses}$ & & & 2.76-04 & \\
\hline \multirow[t]{2}{*}{ gi704 ontor } & & & Lote-04 & & & & 1.6-01 & \\
\hline & & & anes & thil $4:$ : & & & 20 es & \\
\hline $9 a 1 \pi 0$ & & & Laties & 3esses & \multicolumn{2}{|c|}{ 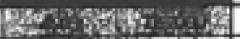 } & 243E-05 & soses \\
\hline $\operatorname{san} m$ & 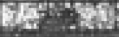 & 45 & LeAE & Ioxes & \multirow{2}{*}{\multicolumn{2}{|c|}{ 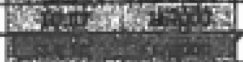 }} & $6.2 \pi-05$ & Was \\
\hline gavios toted & & & Ixtes & $203-6$ & & & 4tases & GTE-S \\
\hline
\end{tabular}

Please use 93170 as part of the LEU TRISO lot blend.

Douglas Marshall

On Fri. Feb 17, 2017 at 7:18 AM, Keeley, Joseph T (Joe) <itkeeley@bwxt.com> wrote:

I made an error and corrected it in the table. I added the failure fractions and what I should have totaled all failed parts and divided by the total number of particles. The conclusion is still the same, we made significant improvements.

From: Keeley, Joseph T (Joe)

Sent: Friday, February 17, 2017 8:49 AM

Tot 'opamarshallifgmail.com'

Cc: Navollo, David W; Nledzlalek, Scott E; Rjchardson, W C (Clay); Jones, Aaron C; Mulreany, Robert E

Subject: AGR Burn Leach results

Doug, 
TEM-10200-1

$03 / 01 / 2012$

ENGINEERING CALCULATIONS AND ANALYSIS

Page B4 of B4

Rev. 06

Title:

Acceptance of Nonconforming Fuel for the AGR-5/6/7 Irradiation Experiments

ECAR No.: 3873

Rev. No.: 0

Project No::

23841

Date: $09 / 26 / 2017$

I've updated the results table with the burn leach results for 93170B. We made significant improvements to both the pre-leach and post-leach results and are now with specification. I know Dave set a teleconference for $11 \mathrm{am}$, but if the results look good to you and we can go ahead processing, please call me sooner (434-522-

6177). I'd like to try and get our Operations group working on this as soon as possible.

Thanks,

Joe

This message is intended only for the individual or entity to which it is addressed and contains information that is proprietary to BWX Technologies, Inc and/or its affiliates, or may be otherwise confidential. If the reader of this message is not the intended recipient, or the employee agent responsible for delivering the message to the intended recipient, you are hereby notified that any dissemination, distribution or copying of this communication is strictly prohibited. If you have received this communication in error, please notify the sender immediately by return e-mail and delete this message from your computer. Thank you. 
TEM-10200-1

$03 / 01 / 2012$

ENGINEERING CALCULATIONS AND ANALYSIS

Page C1 of C3

Rev. 06

Title: $\quad$ Acceptance of Nonconforming Fuel for the AGR-5/6/7 Irradiation Experiments

ECAR No.: 3873

Rev. No.: 0

Project No.:

23841

Date: $09 / 26 / 2017$

\section{Appendix C}


TEM-10200-1

$03 / 01 / 2012$

ENGINEERING CALCULATIONS AND ANALYSIS

Page $\mathrm{C} 2$ of $\mathrm{C} 3$

Rev. 06

Title: $\quad$ Acceptance of Nonconforming Fuel for the AGR-5/6/7 Irradiation Experiments

ECAR No.: 3873

Rev. No.: 0

Project No: :

23841

Date: $09 / 26 / 2017$

05/21/2017 03:14 rAA 4545225410

BWAI HIKI

फण

Enxt

DOCUMENT TRANSMITTAL FORM

N-74 Rev. 2 (02/26/16) (CR-1044961-01) Page 1 of 1

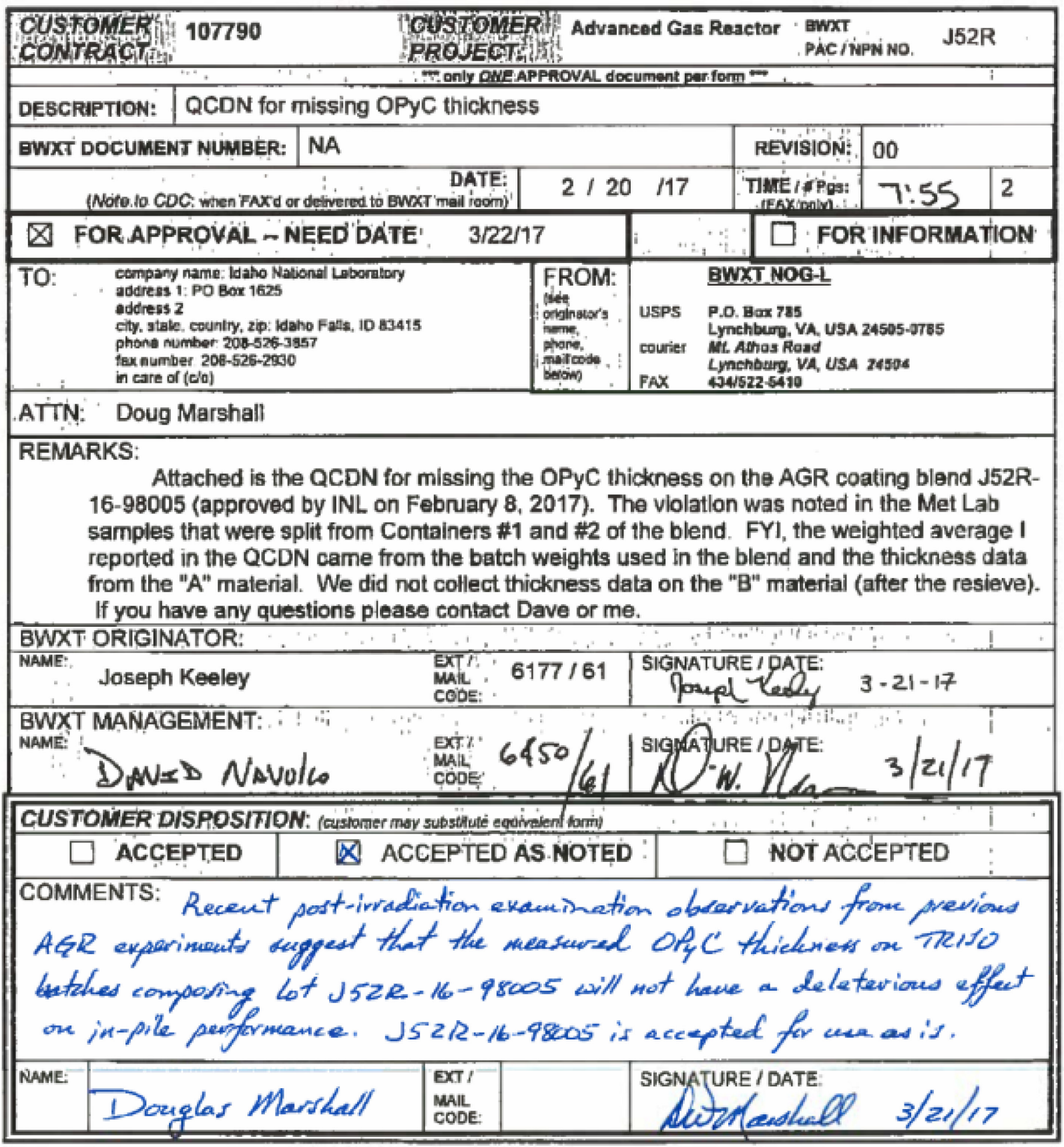

ADMinistrative Review: Ko A faulles $3 / 2 / 17$
KA Hartless 
TEM-10200-1

$03 / 01 / 2012$

ENGINEERING CALCULATIONS AND ANALYSIS

Page C3 of C3

Rev. 06

Title: $\quad$ Acceptance of Nonconforming Fuel for the AGR-5/6/7 Irradiation Experiments

$\begin{array}{lllll}\text { ECAR No.: } 3873 & \text { Rev. No.: } 0 & \text { Project No.: } 23841 & \text { Date: } 09 / 26 / 2017\end{array}$

ВWAI HIKI

फอบน




TEM-10200-1

03/01/2012

Rev. 06

Title:

Acceptance of Nonconforming Fuel for the AGR-5/6/7 Irradiation Experiments

ECAR No.: 3873
Project No.:

23841

Date: $09 / 26 / 2017$

\section{Appendix D}


TEM-10200-1

$03 / 01 / 2012$

ENGINEERING CALCULATIONS AND ANALYSIS

Page D2 of D4

Rev. 06

Title: $\quad$ Acceptance of Nonconforming Fuel for the AGR-5/6/7 Irradiation Experiments

ECAR No.: 3873

Rev. No.: 0

Project No.: 23841

Date: $09 / 26 / 2017$

$09 / 11 / 2017 \quad 10: 35$ FAX 4345225410

BVIT RTRT

ه 001

BNDT.

DOCUMENT TRANSMITTAL FORM

N-74 Rev. 2 (02/26/16)

(CR-1044961-01) Paga 1 of 1

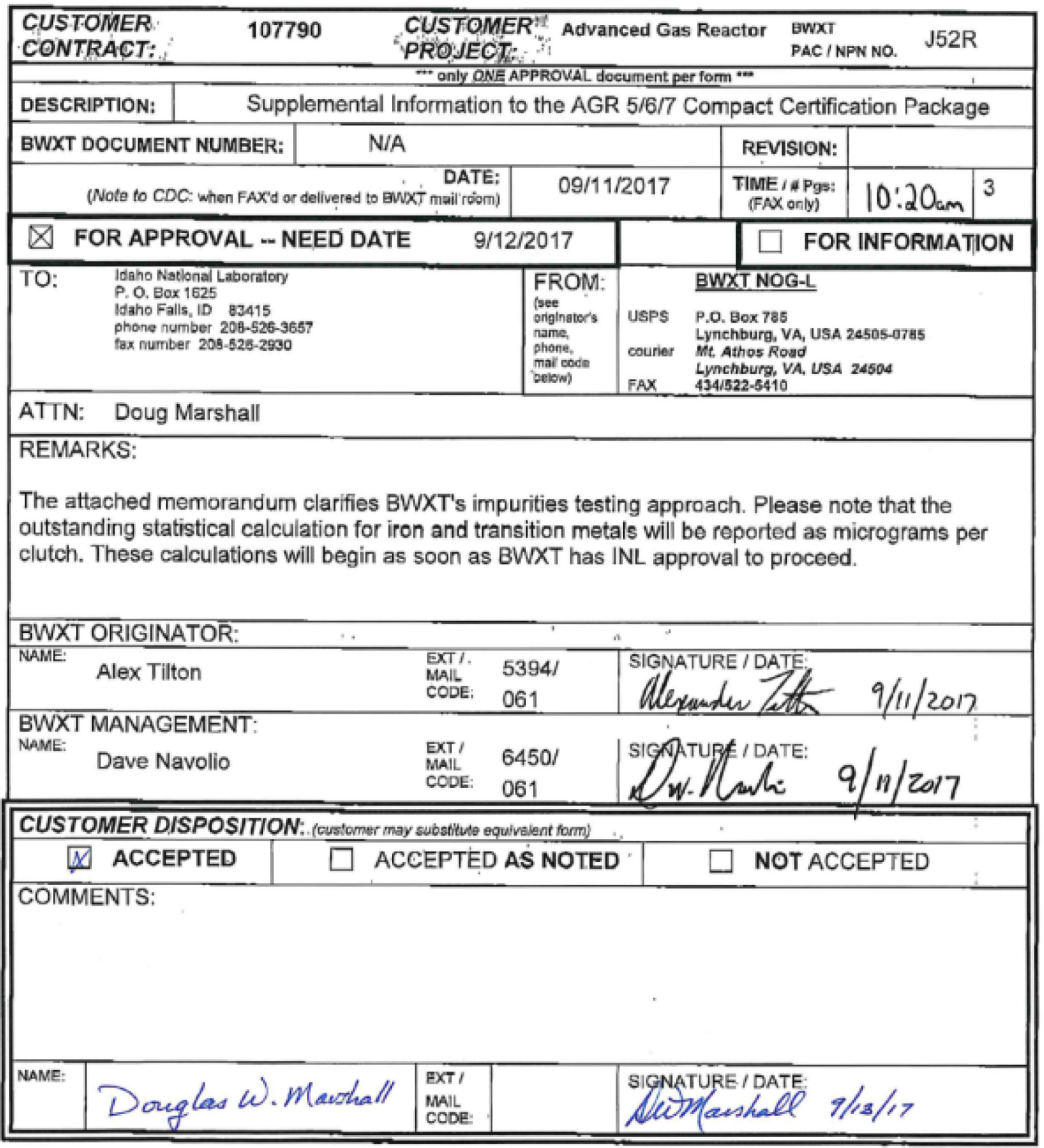

ADMINISTRATIVE REVIEW: 
Rev. 06

Title:

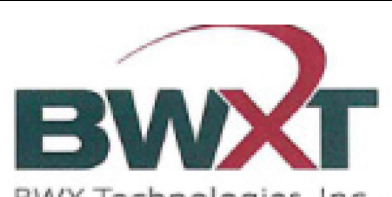

BWX Technologies, Inc.

Testing of the impurities present in the AGR 5/6/7 Compacts was specified in INL Documents SPC-1352 and PLN-4352. The limits for each metallic impurity are listed in the respective table in the two documents. To summarize the process that is used for the impurity testing, a set of randomly sampled compacts from each lot are selected. The number of compacts selected for each lot is determined by the number of TRISO particles per compact and the statistical confidence required for the reported results. Once the compacts have been removed from the lot, they are placed into one container and transferred to the BWXT Chemistry Laboratory. The compacts are randomly removed from the container into groups of five compacts, known as a clutch of compacts, or clutch. The compacts in each clutch are deconsolidated into TRISO particles and residual solids using an electrochemical process with nitric acid. Following deconsolidation, the solution is leached at just below the boiling point of the acid. The solids and the TRISO particles are separated from the solution and all the solids (including the TRISO particles) are burned to remove the excess carbon. Following the bum, the residual solids are again leached in hot nitric acid. Samples of the solution prior to the burn and post-burn are retained for impurity testing. The impurity testing is done using an ICP-MS (Inductively Coupled Plasma Mass Spectrometer). Each sample (pre-burn and post-burn by clutch) is first diluted using a dilution factor of 200 to minimize the corrosive effects of the acid inside the torch. The diluted sample is injected into the torch of the ICP-MS (Nu Instruments Attom HR ICP-MS, Figure 1) and the analyzer is tuned to the specified elements. The mass spectrometer records the counts associated with each specified elements. The conversion of the counts to concentration is done using a parts-per-billion (ppb) calibration curve obtained using standards. The ppb concentration corresponding to the accumulated counts is further corrected for the dilution factor prior to being reported by the unit. A lower detection limit (LDL) for each element is established by the chemist based upon the precision and confidence found at the lower concentration levels found in the samples. If the elemental value for a given sample is reported to be less than the $L D L$, the LDL value is used. If the elemental value is greater than the LDL, then the reported value is used. Note that during the

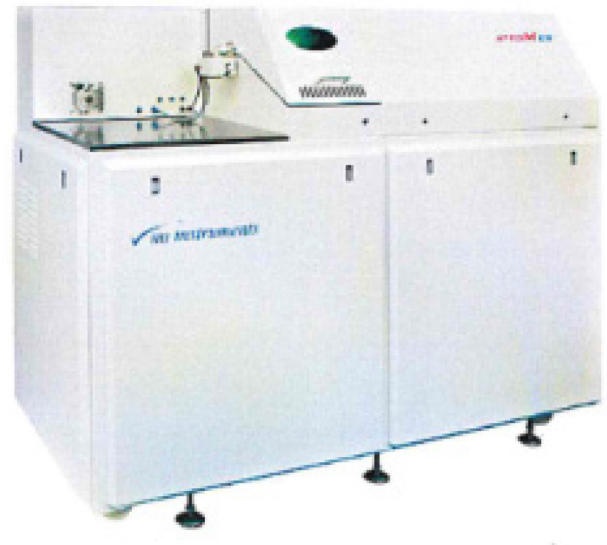

Figure 1: Attom High Resolution ICP-MS previous discussion, the sample under analysis was obtained from a clutch of five compacts. The requirement in the two INL documents referenced above was that the results be reported in micrograms per compact $(\mu \mathrm{g} / \mathrm{compact})$. If the result reported by the analysis was greater than the $L D L$, then dividing the result by five would produce the desired unit. However, for cases where the reported

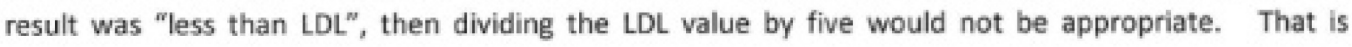


TEM-10200-1

$03 / 01 / 2012$

ENGINEERING CALCULATIONS AND ANALYSIS

Page D4 of D4

Rev. 06

Title:

Acceptance of Nonconforming Fuel for the AGR-5/6/7 Irradiation Experiments

ECAR No.: 3873

Rev. No.: 0

Project No: :

23841

Date: $09 / 26 / 2017$

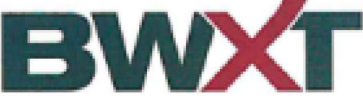

BWX Technologies, Inc.

because the LDL had been determined by the reproducibility of the ppb calibration curve, which was independent of the number of compacts under test. Therefore, for those samples with elemental results reported at the LDL value, the minimum division possible is the clutch. For those situations, the desired unit of $\mu \mathrm{g} /$ compact cannot be achieved.

Table 1 below demonstrates that the results for iron and the Transition Metals were all below the LDL for all samples. Note also in the table that the results are listed as $\mu \mathrm{g} / \mathrm{clutch}$. The results in the table will be forwarded to the BWXT Statistical Department for the remaining statistical calculations, as defined in the INL Specifications.

\begin{tabular}{|c|c|c|c|c|c|c|c|}
\hline \multirow[b]{2}{*}{ Lot } & \multirow[b]{2}{*}{ Sample \# } & \multicolumn{6}{|c|}{ MS Detection Limit ( $\mu$ /dolutch) } \\
\hline & & $\mathrm{Fe}$ & Co & $\mathrm{Cr}$ & Mn & Ni & Sum $\mathrm{Co}_{0}, \mathrm{Cr}, \mathrm{Mn}, \mathrm{Ni}$ \\
\hline J52R-16-14154C & 1 & $<5$ & $<10$ & $<25$ & $<10$ & $\leq 10$ & 55 \\
\hline I5:2R-16-14154C & 2 & $<5$ & $<10$ & $<25$ & $<10$ & $<10$ & 55 \\
\hline 15:2R-16-14154C & 3 & $<5$ & $<10$ & $<25$ & 40 & $<10$ & 55 \\
\hline J52R-16-14154C & 4 & 5 & $<10$ & 25 & $<10$ & $<10$ & $<55$ \\
\hline 152R-16-14154C & 5 & $<5$ & $<10$ & 25 & $<10$ & $<10$ & $<55$ \\
\hline I52R-16-14154C & 6 & $<5$ & $<10$ & 25 & $<10$ & 410 & $<55$ \\
\hline I52R-16-14155C & 1 & 5 & $<10$ & $<25$ & $<10$ & $<10$ & $<55$ \\
\hline 152R-16-14155C & 2 & $<5$ & $<10$ & 25 & $<10$ & $<10$ & $<55$ \\
\hline J52R-16-14155C & 3 & $<5$ & $<10$ & 25 & $<10$ & $<10$ & $<55$ \\
\hline 152R-16-14155C & 4 & $<5$ & $<10$ & 25 & $<10$ & $<10$ & $<55$ \\
\hline 152R-16-14155C & 5 & 45 & $<10$ & 25 & $<10$ & $<10$ & $<55$ \\
\hline J52R-16-14155C & 6 & $<5$ & $<10$ & $<25$ & $<10$ & 410 & $<55$ \\
\hline J52R-16-14156C & 1 & $<5$ & $<10$ & $<25$ & $<10$ & 40 & $<55$ \\
\hline J52R-16-14156C & 2 & 45 & $<10$ & $<25$ & $<10$ & $<10$ & 455 \\
\hline J52R-16-14156C & 3 & 45 & $<10$ & $<25$ & 40 & $<10$ & $<5$ \\
\hline 152R-16-14156C & 4 & 5 & $<10$ & $<25$ & 40 & $<10$ & $<55$ \\
\hline J52R-16-14156C & 5 & 5 & $<10$ & $<25$ & $<10$ & $<10$ & $<5.5$ \\
\hline J52R-16-14156C & 6 & $<5$ & $<10$ & $<25$ & $<10$ & $<10$ & $<55$ \\
\hline J52R-16-14157C & 1 & $<5$ & $<10$ & 25 & $<10$ & $<10$ & $<55$ \\
\hline J52R-16-14157C & 2 & $<5$ & $<10$ & $<25$ & $<10$ & $<10$ & $<55$ \\
\hline J52R-16-14157C & 3 & $<5$ & $<10$ & $<25$ & $<10$ & $<10$ & 455 \\
\hline $\mathrm{J} 52 \mathrm{R}-16-14157 \mathrm{C}$ & 4 & $<5$ & $<10$ & 25 & $<10$ & $<10$ & $<55$ \\
\hline J52R-16-14157C & 5 & $<5$ & 410 & $<25$ & $<10$ & $<10$ & $<55$ \\
\hline J52R-16-14157C & 6 & $<5$ & $<10$ & $<25$ & 410 & $<10$ & $<5$ \\
\hline
\end{tabular}

Table 1: Summary Impurity Data 